\title{
Determination of Hydrochlorothiazide in Plasma by High Performance Liquid Chromatography (HPLC)
}

\author{
Hermann $\mathrm{TW}^{1 *}$, Chavan $\mathrm{SP}^{2}$ and Kostenbauder $\mathrm{HB}^{2}$ \\ ${ }^{1}$ Department of Physical Pharmacy and Pharmacokinetics, University of Medical \\ Sciences, Poland \\ 2Division of Pharmaceutics and Pharmaceutical Analysis, University of Kentucky, \\ Lexington, USA
}

\section{Research Article}

Volume 2 Issue 1

Received Date: January 05, 2018

Published Date: January 10, 2018

*Corresponding author: Tadeusz W Hermann, Visiting post-doctoral fellow from Department of Physical Pharmacy and Pharmacokinetics, University of Medical Sciences, Poznań, Poland, E-mail: hermann@ump.edu.pl

\section{Abstract}

Retention times for hydrochlorothiazide (HCTZ) and chlorothiazide (CTZ, internal standard) are highly temperature$\left(20^{\circ}-26^{\circ}\right)$ as well as pH-dependent (3.5-6.3). Separation of both drugs is maximized in the pH range 6.3 to 6.9. The 10:90 $\mathrm{v} / \mathrm{v}$ acetonitrile: $0.01 \mathrm{M}$ sodium acetate ratio was necessary to resolve endogenous interferences. Resolution with this mobile phase was sufficient to permit quantitation at $225 \mathrm{~nm}$, where absorbance is almost twice that obtained at the absorption maximum $(270 \mathrm{~nm})$. Calibration curves of peak height ratio versus concentration were linear over the concentration range of $20-700 \mathrm{ng} / \mathrm{ml}$, and the intercept was essentially zero.

Keywords: Hydrochlorothiazide; Human plasma; HPLC; Reverse phase; Internal standard; pH effect

Abbreviations: HCTZ: Hydrochlorothiazide; CTZ: Chlorothiazide

\section{Introduction}

Several analytical procedures, including gas liquid chromatography with electron capture detection and normal phase as well as reverse phase HPLC have been shown to be of sufficient sensitivity $(<25 \mathrm{ng} / \mathrm{ml})$ and specificity for quantitation of HCTZ (6-chloro-3,4dihydro-2H-1,2,4-benzothiadiazine-7-sulfonamide 1,1dioxide) in human plasma after ingestion of a single dosage unit of the drug [1-6]. In attempting to apply one of the above procedures of the necessary sensitivity in our laboratory there was found in some plasma samples an apparently endogenous interference which made it impossible to quantitate HCTZ [5]. Through procedural changes such as optimization of $\mathrm{pH}$ for extraction, introduction of an acid wash of the ethyl acetate extract, we use $5 \mu \mathrm{m}$ reverse phase packing material, and modification of the mobile phase, it was possible to eliminate interference with HCTZ quantitation and to eliminate occasional extraneous peaks of long retention time. The method provides efficient separation of HCTZ from CTZ, allowing the latter to be used as internal standard, and potential allowing HCTZ to be used as an internal standard for quantitation of CTZ.

\section{Experimental}

\section{Materials}

HCTZ and CTZ were obtained from Merck Sharp \& Dohme (West Point, PA, U.S.A.). Ethyl acetate (Fisher Scientific, Fair Lawn, NJ, U.S.A.), methanol (Fisher Scientific, Fair Lawn, NJ, U.S.A.) and acetonitrile (J. T. Baker, Philipsburg, NJ, U.S.A.) were of HPLC grade. Ethyl 


\section{Open Access Journal of Pharmaceutical Research}

acetate and methanol were distilled from glass; undistilled methanol yielded a peak eluting at approximately $13 \mathrm{~min}$ at $26^{\circ}$. Water was house distilled and all other chemicals were of reagent grade (Fisher Scientific, Fair Lawn, NJ, U.S.A.). Pooled human plasma was purchased from the Central Kentucky Blood Center.

\section{Apparatus}

A Milton Roy (Rivera Reach, Fl, U.S.A.) Minipump model 396/2396 and a Waters (Milford, MA, U.S.A.) Wisp 710A auto samplers were coupled to a $5 \mu \mathrm{m}$ Ultrasphere-ODS $(4.6 \times 250 \mathrm{~mm})$ reversed phase column (Altex Scientific, Berkeley, CA, U.S.A.). The analytical column was protected by a guard column ( 40 x $4.6 \mathrm{~mm}$ ID) packed with Co: Pell ODS (Whatman, Clifton, NJ, U.S.A.). Absorbance of eluent was monitored at $225 \mathrm{~nm}$ with a Varichrom variable wavelength model VUV-10 detector (Varian Associates, Palo Alto, CA, U.S.A.). The absorbance output (2 AU/V) of the detector was connected to both channels of Houston Omniscibe recorder (Houston Instruments, Austin, TX, U.S.A.). Full range recorder spans of 10 and $100 \mathrm{mV}$ were to provide on-scale peaks.

\section{Mobile Phase}

A mixture of acetonitrile- $0.01 \mathrm{M}$ sodium acetate $(10: 90$ $\mathrm{v} / \mathrm{v}$ ) was filtered through a $0.45 \mu \mathrm{m}$ nylon- 66 membrane filter (Rainin Instrument, Woburn, MA, U.S.A.) and deaerated. The mobile phase was pumped at a rate of 1.4 $\mathrm{ml} / \mathrm{min}$ and developed a pressure of 2600 p.s.i. at $20^{\circ}$.

\section{Stock Solutions and Standards}

Stock solutions containing $0.4,1,2,4,8$, and $14 \mu \mathrm{g} / \mathrm{ml}$ HCTZ and $10 \mu \mathrm{g} / \mathrm{ml} \mathrm{CTZ} \mathrm{in} \mathrm{methanol} \mathrm{were} \mathrm{prepared} \mathrm{and}$ were stable for more than two weeks when refrigerated. One hundred $\mu \mathrm{l}$ of each standard solution was transferred to a $16 \mathrm{~mm}$ culture tube and the methanol was evaporated at $40^{\circ}$ under a stream of nitrogen. To each tube $2 \mathrm{ml}$ of plasma was added after which tubes were closed with PTTE lined screw cap and vortex-mixed for 1 minute. The resulting plasma based standards containing 20, 50, 100, 200, 400 and $700 \mathrm{ng} / \mathrm{ml} \mathrm{HCTZ} \mathrm{and} 500 \mathrm{ng} / \mathrm{ml}$ CTZ were processed according to the extraction procedure described below.

\section{Procedure}

To each $2 \mathrm{ml}$ plasma standard $4 \mathrm{ml}$ of toluene was added. After shaking for 10 minutes and centrifuging for 3 minutes, the toluene layer was aspirated and discarded. Two $\mathrm{ml}$ of $0.2 \mathrm{M}$ phosphate buffer $\mathrm{pH} 6$ and $5 \mathrm{ml}$ of ethyl acetate were added to the remaining solution. After shaking for 10 minutes and centrifuging for 3 minutes, most of the ethyl acetate layer was transferred to a clean tube and $5 \mathrm{ml}$ of $1 \mathrm{M} \mathrm{HCl}$ was added. After shaking for 10 minutes and centrifuging for 3 minutes, the ethyl acetate layer was transferred to a disposable screw cap culture tube and evaporated to dryness under nitrogen flow at $40^{\circ}$. It is essential that ethyl acetate be removed completely; therefore the evaporation step was allowed to proceed for approximately 45 minutes. The residue was reconstituted in $80 \mu \mathrm{l}$ of methanol, and $20 \mu \mathrm{l}$ was injected onto the column.

Plasma samples were processed in the same manner, except that each $2 \mathrm{ml}$ plasma sample was added to a culture tube containing $1 \mu \mathrm{g}$ of CTZ from which the carrier $100 \mu \mathrm{l}$ of methanol was removed by evaporation under nitrogen flow at $40^{\circ}$. Removal of methanol was necessary to prevent formation of an emulsion during extraction with ethyl acetate layer.

Peak height ratios of HCTZ to CTZ were plotted versus HCTZ concentration in $\mathrm{ng} / \mathrm{ml}$, and the resulting calibration curve was used to calculate the plasma concentrations of unknown samples.

\section{Results and Discussion}

As shown in chromatograms for blank and spiked human plasma presented in Figure 1, retention times for CTZ and HCTZ are 8 and 17.5 minutes, respectively, at $20^{\circ}$, providing adequate separation from each other and from endogenous plasma components. Retention time is highly temperature-dependent, being 5.5 and 14.5 minutes, respectively for the same compounds at $26^{\circ}$. Calibration curves of peak height ratio versus concentration were linear over the concentration range of $20-700 \mathrm{ng} / \mathrm{ml}$ and the intercept was essentially zero. The correlation coefficient for 31 determinations was $0.999 \pm 0.0009$. Table 1 presents day to day precision over this concentration range.

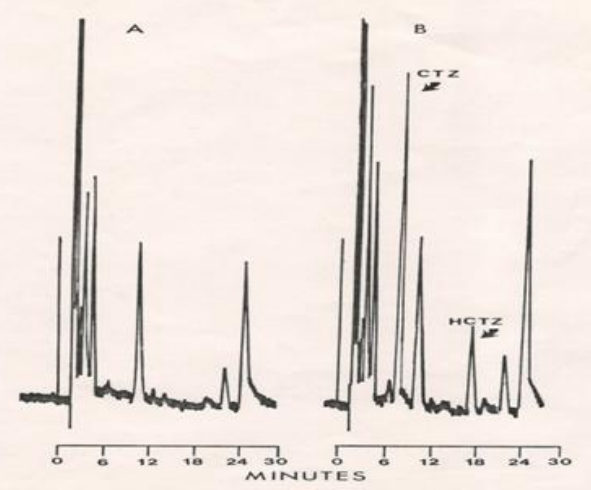

Figure 1: A chromatogram of pooled plasma either blank (A) or supplemented with $100 \mathrm{ng} / \mathrm{ml}$ hydrochlorothiazide (HCTZ) and $500 \mathrm{ng} / \mathrm{ml}$ chlorothiazide (CTZ). 


\section{Open Access Journal of Pharmaceutical Research}

\begin{tabular}{|c|c|c|c|}
\hline $\begin{array}{c}\text { Concentration } \\
\text { in } \\
\text { plasma[ng/ml] }\end{array}$ & $\begin{array}{c}\text { Mean HCTZ conc. in } \\
\text { plasma observed (S.D.) } \\
\text { [ng/ml] }\end{array}$ & $\mathbf{n} \mathbf{a}$ & $\mathbf{\%}_{\mathbf{0}}$ C.V. \\
\hline 20.0 & $19.3(2.3)$ & 5 & 12.2 \\
\hline 50.0 & $50.9(4.4)$ & 5 & 8.6 \\
\hline 100.0 & $100.9(4.0)$ & 6 & 4.0 \\
\hline 200.0 & $194.2(14.7)$ & 6 & 7.6 \\
\hline 400.0 & $399.5(11.4)$ & 6 & 2.8 \\
\hline 700.0 & $703.1(16.8)$ & 3 & 2.4 \\
\hline
\end{tabular}

aNumber of data point at each concentration.

${ }^{b}$ Coefficient of variation in $\%$ or relative standard deviation.

Table 1: Precision data for quantitation of hydrochlorothiazide (HCTZ) in plasma

In addition to using CTZ as internal standard, major changes from the Barbhaiya, et al. procedure [5] included acidification of plasma with $2 \mathrm{ml}$ of $0.2 \mathrm{M}$ phosphate buffer of $\mathrm{pH}$ 6.0, introduction of an $\mathrm{HCl}$ wash of the ethyl acetate extract, and modification of the mobile phase.

The buffer specified in the present procedure reduces plasma $\mathrm{pH}$ to 6.2 prior to extraction. Although Barbhaiya, et al. [5] specified an acetate buffer of $\mathrm{pH} 3.8$, the $0.5 \mathrm{ml}$ of $0.01 \mathrm{M}$ buffer added is not sufficient to reduce the $\mathrm{pH}$ appreciably below $7.0 \mathrm{pKa}$ for HCTZ [5,7]. Acidification of plasma is even more critical for extraction of CTZ which has a pKa of 6.7 [8].

Introduction of an acid wash of the organic phase after extraction of plasma was found by Robinson and Cosyns $\mathrm{L}$ to aid in removal of interfering material and this procedure was applied in the current method [3]. A further wash of the ethyl acetate layer with $5 \mathrm{ml}$ water following the acid wash yields even cleaner chromatograms and allows run time to be reduced; however, there is some loss of CTZ as well, and this procedure was not included in the present method.

Table 2 illustrates the effect of $\mathrm{pH}$ on retention times of HCTZ and CTZ for a mobile phase consisting of acetonitrile: acetate buffer $(15: 85 \mathrm{v} / \mathrm{v})$. Retention times for HCTZ and CTZ decline as pH of acetate buffer is increased from 3.5 to 5.0. From pH 5.0 to 5.4 there appears to be a slight increase in retention, and then from 6.3 to 6.9 retention time again decreases. More importantly, separation of HCTZ from CTZ is maximized in the latter $\mathrm{pH}$ range. The 15:85 v/v acetonitrile: acetate buffer mobile phase is adequate for many plasma samples, but the $10: 90 \mathrm{v} / \mathrm{v}$ ratio was necessary to resolve endogenous interferences observed in some samples. Resolution with this mobile phase was sufficient to permit quantitation at $225 \mathrm{~nm}$, where absorbance is almost twice
[3] that obtained at the absorption maximum of approximately $270 \mathrm{~nm}$.

\begin{tabular}{|c|c|c|}
\hline \multirow{2}{*}{ Acetate buffer $\mathbf{p H}$} & \multicolumn{2}{|c|}{ Retention time [min] } \\
\cline { 2 - 3 } & HCTZ & CTZ \\
\hline 3.5 & 14.0 & 12.0 \\
\hline 4.0 & 10.5 & 8.5 \\
\hline 5.0 & 10.0 & 8.0 \\
\hline 5.4 & 11.0 & 9.0 \\
\hline 6.3 & 11.0 & 6.5 \\
\hline 6.5 & 10.5 & 6.0 \\
\hline 6.9 & 9.0 & 5.0 \\
\hline
\end{tabular}

aMobile phase: acetonitrile : $0.01 \mathrm{M}$ acetate buffer $(15: 85$ $\mathrm{v} / \mathrm{v}$ ).

bTemperature: $23^{\circ} \mathrm{C}$, flow rate $=1 \mathrm{ml} / \mathrm{min}$.

Table 2: Effect of $\mathrm{pH}$ of mobile phase on retention time of hydrochlorothiazide (HCTZ) and chlorothiazide (CTZ) $)^{\mathrm{a}, \mathrm{b}}$

\section{Conclusion}

Our method presented is feasible to be used for bioavailability studies of generic $25 \mathrm{mg}$ tablets of hydrochlorothiazide used nowadays in medical practice.

\section{Acknowledgement}

Tadeusz W. Hermann appreciates a great support of late Joseph V. Swintoskyt, former Dean of the College of Pharmacy (1967-1987) University of Kentucky at Lexington, in arranging his visiting post-doctoral fellowship for 7 months as well as of late Harry B. Kostenbaudert, former vice-Dean for Research of this College, in providing his laboratory facilities for research and discussing the results obtained and final writing up of the manuscript. An excellent technical assistance and friendliness of Sunita P. Chavan, B. Sci. was extremely beneficial.

\section{References}

1. Lindstrom B, Molander M, Groschinsky M (1975) Gas chromatographic determination of hydrochlorothiazide in plasma, blood corpuscles and urine using an extractive alkylation techniques. J Chromatogr 114(2): 458-462.

2. Redalieu E, Tipnis VV, Wagner WE Jr (1978) Determination of plasma hydrochlorothiazide levels in humans. J Pharm Sci 67(5): 726-728.

3. Robinson WT, Cosyns L (1978) A sensitive method for the determination of hydrochlorothiazide in serum by
Hermann TW, et al. Determination of Hydrochlorothiazide in Plasma by High Performance Liquid Chromatography (HPLC). Pharm Res 2018, 2(1): 000148.
Copyright@ Hermann TW, et al. 


\section{Open Access Journal of Pharmaceutical Research}

high pressure liquid chromatography. Clin Biochem 11(4): 172-174.

4. Erk N (2003) Simultaneous determination of irbesartan and hydrochlorothiazide in human plasma by liquid chromatography. J Chromatogr B Analyt Technol Biomed Life Sci 784(1): 195-201.

5. Barbhaiya RH, Philips TA, Welling PG (1981) Highpressure liquid chromatographic determination of chlorothiazide and hydrochlorothiazide in plasma and urine: preliminary results of clinical studies. J Pharm Sci 70(3): 291-295.
6. Huang T, He Z, Yang B, Shao L, Zheng X, et al. (2006) Simultaneous determination of captopril and hydrochlorothiazide in human plasma by reverse phase HPLC from linear gradient elution. J Pharm Biomed Anal 41(2): 644-648.

7. (1976) Merck Index, Ninth Edition, Merck \& Co., Inc., Rahway, NJ, 1976, pp: 629.

8. (1961) Chlorothiazide, Medical Publications Department, Merck Sharp \& Dohme Research Laboratories, Rahway, NJ, pp: 6. 